\title{
Property Derivatives for Managing European Real-Estate Risk
}

Frank J. Fabozzi is Professor in the Practice of Finance, Yale School of Management, New Haven, CT

frank.fabozzi@yale.edu

Robert J. Shiller is Arthur M. Okun Professor of Economics, Yale University, New Haven, CT

robert.shiller@yale.edu

Radu Tunaru is Senior Lecturer in Financial Mathematics, Cass Business School, City University, London

r.tunaru@ city.ac.uk 


\title{
Property Derivatives for Managing European Real-Estate Risk
}

\begin{abstract}
Although property markets represent a large proportion of total wealth in developed countries, the real-estate derivatives markets are still lagging behind in volume of trading and liquidity. Over the last few years there has been increased activity in developing derivative instruments that can be utilised by asset managers. In this paper, we discuss the problems encountered when using property derivatives for managing European real-estate risk. We also consider a special class of structured interest rate swaps that have embedded real-estate risk and propose a more efficient way to tailor these swaps.
\end{abstract}

Keywords: real-estate markets, property derivatives, balance guaranteed swaps JEL classification: G15, G20 


\section{Introduction}

The property market represents the largest market in developed countries in Europe and the world, estimated between $30 \%$ and $40 \%$ of the value of all the underlying physical capital. From a theoretical perspective, residential real-estate assets are viewed as a combination of a consumption asset and a leveraged investment. A decade ago Shiller and Weiss (1999) pointed out that this very characteristic poses greater risk for the financial stability for households due to geographic fluctuations in property prices. Clearly, this prediction was realized in the U.S. residential real estate market beginning in 2007. Moreover, consequences were not limited to the U.S. real-estate market but were felt in the market for other financial assets throughout the world.

Ideally, property derivatives on some relevant real-estate indices could be used to mitigate real-estate risk and potential reduce the volatility of property prices. Although real-estate derivatives should be preferred to insurance-type contracts because of direct settlement, the liquidity of property derivatives is key to their utilisation by individuals and professional asset managers. However, liquidity can be established only after banks decide to participate more actively in the real-estate index futures and options markets, as suggested by Case, Shiller, and Weiss (1993). Hinkelman and Swidler (2008) investigated if housing price risk can be hedged with futures on other commodities and financial indices that already trade in the markets. They could not find significant evidence of a systematic relationship between national housing prices and prevailing traded futures contracts. Hence, establishing property futures markets would help to complete the real-estate markets.

Today it is well known now that housing prices are sticky when they are going down, sellers being reluctant to sell at a price below the "psychological" price at which the property was initially purchased, as first noted by Case, Quigley, and Shiller (2003). This makes the 
market more localized, with information asymmetric, and participants' price expectations strongly influenced by the most recent series of prices.

It is less likely, at least for now, that a significant fraction of individual homeowners will hedge directly their house prices. Nevertheless, banks and building societies holding mortgage portfolios more diversified nationally have an incentive to hedge their exposure with property derivatives where the underlying is a local index. The use of index-based futures contracts and options for hedging mortgage risk, default risk, and real-estate price risk has long been advocated by Case and Shiller (1996). Fisher (2005) provides an overview of total return swaps activity in the United States while Clayton (2007) discusses several indices utilised for derivatives trading.

The introduction of derivatives in the real-estate market is not easy because, as noted earlier, liquidity is difficult to establish when returns are predictable. An extensive discussion highlighting the important psychological barriers that need to be passed for the establishment of real-estate derivatives is provided in Shiller (2008). Carlton (1984) argues that if changes in market prices are predictable, then changes in prices cannot be perceived as risky. One major obstacle hindering the introduction and development of real-estate derivatives was the fact that when returns follow trends at certain points in time, the market sentiment is unidirectional, making it is difficult to find counterparties. Nevertheless, we argue in the paper that if a futures contract is already trading for a series of future maturities, then the shape of the forward curve on real-estate index becomes important. Trades may be executed on the curve, trading simultaneously - say short a futures with a long maturity and long a futures with a shorter maturity. Thus, a counterparty in a property derivatives contract does not have to be necessarily a speculator in order to take a position against a market trend. With futures and options on futures, an entire spectrum of trading strategies becomes available and market participants such as hedge funds, investment houses, and private equity funds may 
provide much needed liquidity. For example, Alpha Beta Fund Management (ABFM), an open-end investment company based in Ireland does not invest directly in physical property assets but instead seeks more efficient means for accessing real-estate index returns. The firm targets pension funds and other investors that may benefit from access to British housing by dealing in an over-the-counter property derivatives market which tracks the Halifax House Price Index (HHPI).

The exponential growth of the subprime mortgage market from 2002 to 2007 was driven by the use of securitization as a process of ring-fencing the risks of a collateral portfolio on one side and the introduction of the real-estate collateralized debt obligation (RE CDO) concept on the other side. ${ }^{1}$ The ever-growing demand for credit risky bonds pushed the boundaries of this new structured credit market into new territory, residential mortgagebacked securities (RMBS) backed by home equity loans (i.e., loans to credit impaired borrowers) and commercial mortgage-backed securities (CMBS). The cash flows of a RMBS, CMBS, and RE CDO depend fundamentally on the performance of a pool of mortgage loans, which in turn depend on the behavior of individual homeowners and commercial borrowers. These real-estate structured products are radically different from a corporate $\mathrm{CDO}$ where the collateral consists of corporate credits whose corporate names could be monitored and their balance sheet scrutinized regularly. Hence, the real-estate risk drivers - prepayments and defaults clustering and timing - as well as recovery rates, could influence the financial stability of companies and institutions not directly related to the spot real-estate market. Hedging the potential disruption of scheduled cash flows is not an easy task and there are only a few instruments available in the market.

The advances in futures markets on real-estate indices may improve efficiency in spot markets and improve price discovery. Since transaction costs are high and create a barrier for

\footnotetext{
${ }^{1}$ RE CDOs are also known as structured finance CDOs.
} 
entry into spot markets, futures markets may also help indicate the level of spot prices for future and current market volatility. Another benefit of real-estate derivatives is that they are useful tools that allow investors access to an important asset class that would be hard to access otherwise. Indeed, the capital asset pricing model (CAPM) has as a fundamental results that investors should be holding all risky assets in proportion to the amounts outstanding, which suggests that real estate should be a major element in all portfolios involving risky assets. Furthermore, due to the lack of correlation of housing prices with equity prices, expanding diversified portfolios to include real estate could be highly beneficial, particularly for those who do not now invest significantly in a diversified portfolio of real estate, including many insurance companies and pension funds. A further of this benefit is provided by Webb, Curcio, and Rubens (1988) and Seiler, Webb, and Myer (1999). In addition, Englund, Hwang, and Quigley (2002) point out that there could be large potential gains from instruments that would allow property holders to hedge their lumpy investments in housing.

Obviously, the first step in hedging is the selection of a suitable hedging instrument. A primary factor in deciding which derivative contract will provide the best hedge is the degree of correlation between the factors that drive the price of the derivative instrument under consideration as the hedging vehicle and the underlying risk which investors seek to eliminate. Correlation is not, however, the only consideration when the hedging program is of significant size. If, for example, an investor wants to hedge a very large cash position, liquidity becomes an important consideration and it might be necessary to split the hedge among two or more different types of derivatives.

Real-estate derivatives are useful to several categories of end users. The first category consists of individuals who are property owners and private investors specializing in real estate. Although this category of users is very large, in practice, not many may employ 
property derivatives due to knowledge and transaction costs barriers. The second category consists of asset managers hedging their price risk exposure in both domestic and foreign real estate. An adjacent category includes dealers and portfolio managers in structured products seeking to hedge their positions. Finally, real-estate derivatives can be embedded by structurers into newly designed structured products. The risks that users in these categories are hedging with property derivatives may vary. For example, while the members of the first category will hedge price risk, the users in the other categories may also consider property derivatives in connection with interest-rate risk and, possibly, currency risk.

Property derivatives can have many applications. The most basic one is for hedging a trade in synthetic assets such as forward or total return swaps in order to recoup the potential loss on primary real-estate assets. Another important application is portfolio diversification or tactical allocation. Consider an investor or hedge fund seeking to get exposure to U.K. real estate without buying physical property in the UK because the anticipated appreciation may take a long time to be realized and carries high transaction costs. The investor could simply buy futures contracts on Eurex. An important application that should not be overlooked is the replication of market beta. Since real-estate markets represent such a high proportion of the world market, it is inconceivable to achieve market beta on a portfolio that does not include real-estate. Hence, for diversification purposes, a global asset manager should have a position in property markets and derivatives offer the best tool to achieve that at a reduced cost of entry and of exit. Property funds can adjust sector allocations and can invest in sectors of the market where they would not normally operate. The so-called country swap trades, where an investor trades in opposite directions on real estate indices in two different countries, may allow the shifting in risk allocation or taking advantage of structural breaks of property index series in one country while things remain unchanged in the other. Investors may also arbitrage pricing inconsistencies between the property derivatives and real estate investment 
trusts (REIT) markets. Furthermore, it is also possible to have imbalances of supply/demand among property markets themselves that may occur due to various factors, such as investor sentiment driven by news about possible events or changes in monetary policy. Pension funds may decide to alter asset allocation to property without actually trading in the underlying asset (i.e., employing an asset allocation overlay strategy with derivatives).

In this paper, we describe the real-estate derivatives available worldwide and discuss the issues related to the pricing of these instruments and to the managing of hedging instruments over time.

\section{Financial instruments related to property risk}

In this section, we describe the development of real-estate linked derivatives in Europe. The most developed market from a financial product innovation point of view is the United Kingdom, with growing activity noticed recently in other developed European countries too. The instruments can be classified by the type of real-estate risk they are hedging (1) housing price risk, (2) commercial property price risk, and (3) mortgage loan portfolio amortizing risk.

\subsection{Hedging Housing Price Risk}

A major component of the real-estate asset class is represented by residential housing. Housing prices are determined by macroeconomic and credit market conditions and by the behaviour of the individuals buying and selling properties. We have seen in recent experience that there is indeed a risk of sharp downturn or fall in housing prices. In addition to the owner of the property, this risk is a major concern to banks and other lending institutions and investors in structured products backed by residential mortgage loans. Here we review the financial instruments that have been designed to be used for hedging this risk. 
In 1991 the London Futures and Options Exchange (FOX) launched trading in residential futures (as well as commercial property futures). The contracts were based on a hedonic index of property prices. However, the markets lasted only three months, from May to October, and ended with a wash trading scandal. ${ }^{2}$

In the United Kingdom, residential real-estate derivatives are written on a house price index, the most common being the HHPI series, the longest running monthly housing price series with data available since January 1983. This hedonic index is based on the largest monthly sample of mortgage data, typically covering around 15,000 house purchases per month.

In 2003, Goldman Sachs issued the first series of a range of covered warrants based on the Halifax All-Houses All-Buyers seasonally-adjusted index on the London Stock Exchange (LSE). More recently, based on the HPPI, in August 2007, Morgan Stanley agreed on an exotic swap with an undisclosed counterparty, worth more than $£ 1$ million. This is the UK's first residential property derivative trade that included an embedded exotic option, a "knock-in put" option. This derivative allows the counterparty to gain if the HHPI rises subject to a maximum payout. The investor's capital is protected unless the HHPI falls below an initially specified value.

\subsection{Hedging Commercial Property Price Risk}

The other major component of the real-estate asset class is represented by commercial properties. Price risk for commercial properties is similar to housing price risk but it is not generally influenced by the behaviour of the same participants as in the residential housing market. Commercial property prices are determined by supply and demand and specialized market participants. Although some degree of correlation is expected between commercial

\footnotetext{
${ }^{2}$ We omit here discussion of spread-betting markets for home prices, such as have been offered in the UK by CityIndex.co.uk, IGIndex.co.uk and Spreadfair.co.uk, because these did not appear to be used generally for risk management and all of these markets have been shut down as of 2008
} 
price risk and housing price risk, there are sufficient differences between these two risk to warrant a separate analysis and separate hedging instruments.

The major underlying capturing the dynamics of the commercial real-estate in the United Kingdom and continental Europe is the family of Investment Property Databank (IPD) indices. The IPD UK Monthly index is based on open market appraised valuations compiled from 74 monthly valued funds (around 3,700 properties) worth around $£ 56$ billion. It includes commercial and other investment properties representing more than $90 \%$ of the combined value of the property assets held in UK unit trusts and other unit linked property investment funds. Derivatives are issued contingent on the IPD UK Annual index which has a slightly different calculation methodology. It is envisaged in the future that derivatives on IPD will be issued on a quarterly IPD index. The index has been franchised on a large scale in Europe.

After the failure in 1991 of the London Fox commercial property futures, activity moved to the over-the-counter (OTC) market. The instrument that survived was the property income certificate. Patel (1994) suggests that the failure of the FOX property futures contract was attributable to the problems in the construction of the index that caused lag dependence, and to a lesser extent the cash-market illiquidity that led to considerable time-basis risk. Just three years after the failure of the FOX contracts, Barclays began issuing its Property IndexCertificates in 1994 and its Property Index-Forwards in 1996, with the index comprising UK commercial property only. The contracts are currently traded in the OTC market and are issued on two monthly indices published by IPD: the IPD Total-Return and IPD CapitalGrowth indices. These contracts have maturities of three to four years.

The property derivatives market has expanded in the United Kingdom from $£ 850$ million in $2005, £ 3.9$ billion in 2006 to $£ 7.2$ billion in 2007 . The IPD Index Property Derivatives volume in 2008 was $£ 7.73$ billion, not far from $£ 8.30$ billion in 2007’s record 
year. In Europe, in 2007 the trading volume on the IPD French All Office Index was $£ 787$ million, compared to $£ 283$ million on the German All Property Index. The first French property swap on the IPD France Offices Annual index was traded in December 2006 by Merrill Lynch and AXA Real Estate Investment Managers. The first option on an IPD index outside the United Kingdom was referenced to the German IPD/ DIX Index and it was traded in January 2007 with Goldman Sachs acting as a broker. Other European markets where property derivatives have been traded include Switzerland and Italy. Thirteen major investment banks acquired licenses for the IPD index family, although some of these banks went into bankruptcy or have been acquired by other banks. In Europe, property derivatives written on IPD indices traded OTC with a notional over $£ 18.8$ billion in trades executed by October 2008.

Eurex began trading property futures on February 9, 2009. These futures contracts are annual contracts based on the total returns of the IPD UK Annual All Property Index ${ }^{3}$ for individual calendar years. With the introduction of this futures contract, the Eurex seeks to eliminate counterparty risk, to improve liquidity to the commercial property sector of the real-estate property market, and to attract a complete range of potential participants in this asset class. Additional futures contracts are going to be launched by Eurex on IPD property indices, such as UK sector indices (Offices, Retail, Industrial) and other European indices (initially France and Germany) on a demand-led basis.

Proposals for improved commercial real estate indices and instruments based on them will find their way into the market. For example, Horrigan et.al (2009) demonstrate how to construct segment-specific indices of property market returns from REIT return data, bond data, and property holding data, as well as how to use those indices to make pure, targeted

\footnotetext{
${ }^{3}$ At the end of 2007 , the IPD index covered 12,234 properties with a total value of $£ 184$ billion - equivalent to $49 \%$ of the UK investment market. The IPD UK Annual Property Index measures unleveraged total returns to direct UK property investments and it is calculated using a time-weighted methodology with returns computed monthly and thereafter compounded for the purposes of the annual index construction.
} 
investments in the commercial real estate market while retaining the liquidity benefits of the well-developed public market in REITs. It is possible to reconstruct the indices at daily frequency without significant increases in noise and at various levels of segment granularity. Moreover, it seems that these new indices suggested by the authors lead transactions-based direct property market indices during market turns. Thus, these REIT-based commercial property return indices have the potential to be used to develop hedging strategies in the realestate market and support derivatives trading.

In the commercial mortgage-backed securities (CMBS) market several dealers have offered swaps on various CMBS indices and their subsectors. Goodman and Fabozzi (2005) provide insight into the mechanics and the economic rationale of the total return swaps issued on these indices. They also explain the attraction to those who want to get exposure to a CMBS in a synthetic way.

\subsection{Mortgage loan portfolio amortizing risk}

At the portfolio level, mortgage loans carry two intrinsic risks that require hedging tools: default risk and prepayment risk. Default risk is the risk of loss of principal and/or interest due to the failure of the borrower to satisfy the terms of the lending agreement. This risk is high for RMBS that are backed by mortgage pools containing subprime mortgages (or non-conforming mortgages ${ }^{4}$ as they are called in the U.K. market). In the United Kingdom subprime mortgages are loans made to borrowers who are viewed as having greater credit risk - borrowers who do not have a credit history and borrowers having a history of failing to meet their obligations.

\footnotetext{
4 The classification of loans in Europe by borrower credit is different from that in the United States mortgage market where loans are classified as prime and subprime loans. Prime loans are then classified as those that are conforming and those that are non-conforming. By non-conforming it is meant that the borrower or the property fails to meet the underwriting standards of Ginnie Mae, Fannie Mae, or Freddie Mac. Thus, in the United States, a non-conforming mortgage can be a prime or subprime mortgage.
} 
A prepayment is the amount of principal repayment that is in excess of the regularly scheduled repayment due. A prepayment can be for the entire amount of the remaining principal balance (i.e., complete payoff of the loan) or for only part of the outstanding mortgage balance (referred to as a curtailment). Prepayment risk is greater for RMBS than CMBS because commercial loans have provisions to mitigate prepayment risk both at the loan level due to lockout periods, prepayment penalties, yield maintenance, and defeasance, and at the structure level..

From an investor's perspective, prepayment risk is the risk that borrowers will prepay their loan (in whole or in part) when interest rates decline. This action by borrowers would force investors to reinvest at lower interest rates. Note that if borrowers prepay when interest rates rise, prepayments are beneficial to investors because proceeds received can be reinvested at a higher interest rate. From the perspective of a portfolio manager or risk manager who is seeking to hedge an RMBS position against interest rate risk, prepayment risk exists even if prepayments occur when interest rates rise. This is because in establishing a hedge, the amount to be hedged will vary depending on a projected prepayment rate. At the outset of a hedge, an amortization schedule is projected based on the projected prepayment rate. Actual prepayment experience of a hedged asset or can cause a deviation between the projected principal outstanding based on the amortization schedule designed at the outset for the hedging instrument and the actual principal. This can result in over or under hedging a position. This stochastic nature of the amortization scheduled due to stochastic prepayments that hedgers face might more aptly be described as "amortization risk".

In Europe, dealers holding inventory for whole loans waiting to be securitized or securitized products held in inventory, as well as asset managers, are exposed to interest rate risk linked to the amortization of mortgage loan portfolio dynamics. The amortization is stochastic and is driven mainly by prepayment and default speeds. As a response to this type 
of hedging problem, a set of financial instruments linked indirectly to real-estate risk drivers appeared in the market: structured swaps. These swaps have been used by building societies and asset-backed securities desks in major investment banks in the United Kingdom and Europe, to hedge interest rate exposure on mortgage loan portfolios.

\section{INSERT FIGURE 1 HERE}

In addition to the property derivatives discussed earlier, in practice there are three types of structured swaps used by participants in the real-estate market in relation to securitisation: (1) a balance guaranteed swap, (2) a cross-currency balance guaranteed swap, and (3) a balance guaranteed LIBOR-base rate

\section{$\underline{\text { Balance Guaranteed Swaps }}$}

There are many problems related to the design of all three types of structured swaps. One problem is that the collateral coupon leg is paid in arrears since mortgage payments are collected every day in the period. The tenor may also differ from deal to deal, the monthly one being more common because this is also the frequency of mortgage payments and consequently the calculation of defaults and prepayments. Quarterly is also used in the market on occasion. Since the usual reference floating rate is three-month LIBOR, there is a basis between the reference three-month LIBOR collected monthly from the swap and the same reference three-month LIBOR paid quarterly to the note holders that funded the securitisation. Switching to a reference rate of one-month LIBOR does not solve the problem of the basis.

Although the name balance guaranteed swap or LIBOR-base rate guaranteed swap may allude to some form of locking in the level of the total balance for the referencing 
mortgage loan portfolio, the structured swaps do not hedge prepayment risk or default risk because it does not guarantee the balance: on the contrary it is exposed to it. The writer is usually a bank that held the loans in a warehouse before securitising them and therefore it is well aware of the quality of the collateral portfolio. Moreover, there are many instances when a bank may underwrite a balance guaranteed swap based on the information provided on the portfolio by a third party.

Structured swaps became part of the securitization process because their use was mandated by rating agencies in order to hedge the interest rate risk mismatch between fixed coupons collectable from the pool of mortgage loans and the floating coupon payments that have to be paid post securitization to investors. Given the large volume of RMBS deals between 2005 and 2007, one can imagine that there are a good number of institutions holding many positions in this type of swap.

In a balance guaranteed swap the parties to the contract exchange the collected coupons on a collateral portfolio of mortgage loans for a reference LIBOR plus a spread. The notional is the total notional of surviving loans for the period. It is a complex swap where the notional is stochastic, being determined by the prepayments, defaults, and arrears in the referencing portfolio. The total coupon paid on an exchange date is also stochastic for two reasons: (1) the notional on which it is calculated evolves in an uncertain manner and (2) even if the notional is known, because of the different possible mixture of loans surviving in the reference portfolio, the coupon could differ for the same notional.

\section{$\underline{\text { Cross-Currency Balance Guaranteed Swaps }}$}

A cross-currency balance guaranteed swap is a more complex swap product that deals with cross-currency deals whereby the coupons on one leg of the swap and also the notional are determined in a foreign currency. This swap deals with an extra level of risk through its 
foreign-exchange exposure. All characteristics described above for a balance guarantee swap apply but the notional is stochastic and in a different currency. One subtlety with this product is that it also has embedded some macroeconomic risk of the country where the obligors reside. This risk may resurface even if there are no changes in the currencies specified in the swap. For example, the ebbs and flows of the political and social environment in the borrowers' country may cause job losses or price inflation that may, in turn, trigger high default rates in the collateral portfolio.

\section{$\underline{\text { Balance Guaranteed LIBOR-Base Rate Swaps }}$}

To understand our next swap - a balance guaranteed LIBOR-base rate swap - we need to review the linkages between the official base rate and the standard variable rate charged on mortgage accounts by lending banks in the United Kingdom. The official base rate is the rate at which the Bank of England lends to other financial institutions. The Bank of England's Monetary Policy Committee meets every month to determine what needs to be done in response to economic conditions. While the official base rate plays a very important role in these markets, banks have the freedom to use a different rate on their loans, which is the standard variable rate. The standard variable rate is linked directly to the official bank rate, but it is usually a little higher, reflecting factors such as the real rate at which banks borrow from each other, the business costs associated with lending operations, the volume and maturity profile of loans, and the funding arrangements. The standard variable rate is likely to vary from bank to bank and is used to determine the cash flows linked to RMBS. ${ }^{5}$ While a balance guaranteed swap is useful for converting fixed-rate coupons into LIBOR-

${ }^{5}$ In the United States there are variable rate mortgages that lend themselves to hedging in the same way. 
based coupons, there are situations when the collateral pool for RMBS and CMBS, will contain loans that pay variable coupons determined by the variable rate established by the lender. The level of the variable rate is determined by the lending bank in relation to both the base rate determined by the national or federal banks and other funding costs driven by LIBOR-swap rates. In general, the basis between the standard variable rate (or its proxy the official base rate) and LIBOR is almost constant and not very large during periods of low interest rate volatility. However, in turbulent periods, such as the subprime crisis that began in the summer of 2007, the basis between the standard variable rate and LIBOR may increase dramatically.

Mortgage traders therefore employ our third swap, a balance guaranteed LIBOR-base rate swap, to hedge this basis risk. One leg of the swap pays LIBOR plus a spread while the other leg pays the average official base rate during the period. For this type of swap, the LIBOR leg pays the coupon fixed at the beginning of the period but the official base rate leg payment is fixed at the end of the period. The contract allows the notional to be any value within a pre-specified band. The party paying the average base rate has the right to choose the size of the notional at the beginning of each period. This is a difficult economic decision to make because only the LIBOR is known at the beginning of each period.

\section{Methodological issues related to real estate derivatives}

\subsection{The Incompleteness of Property Markets}

Derivatives require homogeneity of the underlying for establishing liquidity in their trading. The lack of homogeneity in real-estate markets was one of the main obstacles to the development of property derivatives. The securitisation mechanism, in contrast, has brought a wider participation in these markets and an increased demand for hedging tools. 
It has been emphasized by Case and Shiller $(1989,1990)$ that the housing market in general is inefficient due to serial correlation and inertia in housing prices, as well as in the excess returns. A possible explanation has been offered by Case, Quigley, and Shiller (2004) who argue that the price expectation of the majority of market participants is backward looking. The real-estate literature suggests that repeat-sales indices have three main characteristics: (1) they are not subject to the noise caused by a change in the mix of sales, (2) they are highly autocorrelated, and (3) they are predictable with a forecast R-squared roughly $50 \%$ at a one-year horizon. The hedonic indices are subject to model risk stemming from the multivariate regressions used to construct those indices. The factors employed in hedonic regressions are those characteristics of properties that have been historically found to explain housing prices. The methods associated with hedonic indices inherit all the common problems known for regression analysis, namely spurious regression, multi-collinearity, and model selection.

When pricing or hedging various instruments, it should be remembered that short sales of real-estate properties is impossible and trading may not be feasible for fractional units. These unique characteristics of real-estate properties have profound implications regarding valuation principles. They strongly violate the assumptions of he Black-Scholes framework, that instantaneous trades in and out are not only feasible but also costless.. Moreover, the predictability in housing prices makes it difficult to establish hedging procedures. However, one may argue that a well-established futures market may feed information into current prices and some balance can be achieved with a dual information transmission mechanism.

The finance literature dealing with real-estate pricing models can be classified into two main frameworks: equilibrium models and no-arbitrage market models. Geltner and Fisher (2007) is the main reference for the former category. For the latter, the earliest 
reference is Titman and Torous (1989) who considered a credit-risk type of model for pricing commercial mortgages. Buttimer, Kau, and Slawson (1997) were the first to propose pricing real-estate derivatives such as total return swaps under a Black-Scholes framework. Their modelling approach was revisited by Bjork and Clapham (2002) who focus on some important theoretical issues related to no-arbitrage models. They proved that the spread of a total-return swap should be zero and point to some approximation errors introduced by Buttimer et.al (1997). Patel and Pereira (2006) extended the no-arbitrage models to include counterparty risk. The value of a real-estate total return swap is no longer zero when counterparty risk is taken into account. The spread over LIBOR is highly dependent on the volatility of index returns and on counterparty default risk. The Black-Scholes risk-neutral methodology was applied by Ciurlia and Gheno (2008) for pricing real-estate derivatives such as European and American options on real-estate assets with a two-factor model. Syz (2008) gives an overview of the markets and discusses pricing of forwards in the BlackScholes framework identifying the deficiencies but not providing a solution.

All the no-arbitrage models just mentioned were formulated within the context of complete markets. However, real-estate derivatives are very much incomplete markets. Otaka and Kawaguchi (2002) developed a model for pricing commercial real-estate under incomplete markets that consists of (1) a security market where stocks, bonds, currencies, and derivative securities are traded without friction, (2) a space market with the rents of buildings, and (3) a property market where the prices of real properties are determined.

More recently, Baran et al. (2008) used the Schwartz and Smith (2000) model for pricing real-estate derivatives. Pricing is considered under a martingale measure and the main innovation of their paper is related to the constrained maximum likelihood method combined with Kalman filter applied for parameter estimation. 
The no-arbitrage argument is difficult to apply because of the impossibility of short selling and the non-homogeneity of the property as an asset. Moreover, the underlying index is only an observable variable and not an asset that could be traded freely without any frictions, although real estate portfolios mimicking exactly the index are a possibility for a distinct class of investors. The new generation of products dependent on real-estate risks cannot be priced in a risk-neutral framework either. This is due to the relationship between interest rate risk along the term structure of interest rates and the risk triggers in RMBS space such as defaults, prepayments, and arrears. Hence, a real-world measure approach based on statistical calibration of historical data is required for pricing real-estate derivatives. A new method focused on the market price of risk as a modelling tool is described by Fabozzi and Tunaru (2009). Their models take into consideration the mean-reversion to a nonlinear long-run trend of real-estate indices.

Property derivatives markets are incomplete because the primary asset underpinning this market suffers from lack of homogeneity. Black (1986) emphasizes that for the smooth functionality of derivatives, a homogeneous underlying asset is helpful. However, similar properties in close geographical proximity should have similar prices. This high correlation is helpful for cross-hedging spot real-estate portfolios with futures on local indices. Nevertheless, the lack of homogeneity implies that hedging with real-estate derivatives is always going to be less than perfect. Baum (1991) remarks that managers of real-estate portfolios with assets worth individually a large amount of money have extra exposure to idiosyncratic risk that cannot be hedged away easily with property derivatives.

An important characteristic to account for when modelling an underlying real-estate index is reversion to a long-run trend. Similar to commodity markets where the underlying asset is a consumption asset, the supply and demand forces on real-estate markets drive realestate prices in a different way than a stock index or bond index. 
Let $\left\{X_{t}\right\}_{t \geq 0}$ be a stochastic process representing a real-estate index. Then consider the process on the $\log$-scale $Y_{t}=\ln \left(X_{t}\right)$. There is a clear linear time trend for the IPD UK Monthly index ${ }^{6}$ since 1986 as illustrated in Figure 2 using a log-scale and for the Halifax House Price Index in Figure 3 based on a quarterly historical series. One could argue that the fluctuations of the observed values of both indices, on the log-scale, are wrapped around a positive linear time trend. A time-trended mean-reverting Ornstein Uhlenbeck process could be appropriate to describe this phenomenon and any model for pricing real-estate derivatives on these indices should account for this statistical property, though care should be taken about the possibility of spurious trend estimation. The failure of an Ornstein Uhlenbeck process to capture short-term momentum may also be a problem.. But as a first approximation it may do, and is in line with the framework proposed by Lo and Wang (2005) for pricing derivatives on assets that are predictable.

\section{INSERT FIGURE 2 HERE}

\section{INSERT FIGURE 3 HERE}

Therefore, we can assume that $\left\{Y_{t}\right\}_{t \geq 0}$ is a process that is mean reverting towards a deterministic linear trend. In other words, the log-index is the sum of a zero-mean stationary autoregressive Gaussian process and a deterministic linear trend. One could also fit nonlinear trends if necessary. It is possible then to calculate the solution of this equation in closed form which can be useful for pricing derivatives. Hence, a real-estate index can be modelled with a geometric Ornstein-Uhlenbeck process that always ensures positive levels. Because the realestate market is incomplete, for pricing purposes one needs to specify exogenously the market price of risk. .

\footnotetext{
6 The IPD Monthly Index is based on an open market appraised valuations of real buildings and it covered 3,700 properties worth around $£ 47$ billion in September 2006. It includes commercial and other investment properties representing more than $90 \%$ of the combined value of the property assets held in UK unit trusts and other unit linked property investment funds.
} 
It is critical to be able to model real-estate indices as close as possible to real-world market conditions since many mortgage-related securities are marked to model in the absence of a liquid market. A large bias in forecasting future levels of a real-estate index will be reflected, say, in marking the profit and loss position of a real-estate position, and this could be extremely detrimental to banks holding positions in these securities.

\subsection{Risk Management Problems of Structured Swaps}

Since it is impossible to determine a priori the future notional and coupons that will be paid, it is very difficult to price a balance guarantee swap with risk-neutral or martingale pricing techniques. Moreover, as the subprime-liquidity crisis has shown, it may be impossible to use the market to retrieve information about key factors affecting valuation. In other words, it may be difficult to mark real-estate positions to market and, as a result, banks and asset managers may need to resort to in-house valuations or marking to model. The only solution is to look at fundamentals, employ historical data, and price cash flows within a riskadjusted framework by aggregating across a large set of simulated scenarios. This approach is rooted in actuarial science and it is appropriate in this context because the notional in these contracts is driven by default risk and prepayment risk. These risks cannot be determined within this market or by real-estate market participants.

The three types of swap described in Section 2.3.,_depending on a stochastic notional, cannot be priced with techniques applied to other interest and credit derivatives. A statistical modelling approach that calibrates data available and that would allow a Monte Carlo exercise for the determination of the probability distribution of defaults and prepayments is necessary. It is far more important, as discussed in Pavlov (2001), to capture the sensitivities of default and prepayment rates to the intrinsic characteristics of the collateral portfolio than being worried about riskless arbitrage situations that are difficult, although not impossible, to 
appear in this context. Advances in interest rate derivatives modelling can still play a role since the future levels of interest rates can be used as an input in these statistical regression models for default and prepayment rates.

The standard method for pricing a balance guarantee swap is to consider a region that will cover the realised amortising balance of the portfolio of loans. Figure 4 describes this technique. The prepayment rate used in the construction of the figure is the conditional prepayment rate $(\mathrm{CPR})$, the measure most commonly used for RMBS. The upper curve is associated with a low CPR while the lower curve is determined from a high CPR. While the upper curve cannot be taken beyond the $0 \% \mathrm{CPR}$, the lower curve choice is determined by the risk appetite of the underwriter of the balance guarantee swap. Hence, the shaded region in Figure 4 represents the risk taken by the seller of this product. If the realised curve moves below the lower curve, then the mechanism of the pricing that is described next does not function.

\section{Insert Figure 4 Here}

The seller will price the balance guaranteed swap with a portfolio of an amortising swap with notional following the upper CPR curve and a series of Bermudan receiver swaptions with notionals determined by the difference between the upper curve and lower curve. The amortising swap will pay a fixed coupon pre-specified by the seller, ideally as close as possible to the total fixed coupons collected from the portfolio of mortgage loans under the low CPR scenario. The swaptions will have an exercise price equal to the difference between the fixed leg rates of the amortising swap and the price of the amortising swap. The frequency and maturities of the swaptions are in correspondence with the amortising swap. The role of the swaptions is to allow the compression of the notional of 
this hedging portfolio when the balance of the collateral portfolio moves below the upper curve and LIBOR decreases. In order to calculate the price of the balance guarantee swap, three elements are considered: (1) the price of the amortising swap (i.e., the spread added to LIBOR to bring the swap on par), (2) the premia of the series of receiver swaptions, and (3) the reserve amount to compensate for unhedged risk. The third element is the shaded region in Figure 4. If the buyer does not want to face any upfront costs, then the first two elements should be transformed into an equivalent running rate.

Nevertheless, there is still a difficult problem the seller of the balance guaranteed swap faces, namely the economic decision when to exercise the swaptions. Exercising any swaptions leads to automatic entry into swaps receiving fixed and paying LIBOR and this process is irreversible. If at a later date the balance of the collateral mortgage loans jumps back again, then there is a danger of possible losses due to periods of low levels of LIBOR. The decision to exercise the swaptions is not easy because LIBOR can easily fluctuate from one period to another. This replicating strategy requires active management and excellent economic forecasting skills of interest rate markets. The structure of payments over one period, usually one month, is described in Table 1.

\section{Insert Table 1 here.}

The major problem in pricing and hedging a balance guarantee swap is the difference between $N_{t}, c_{t}$ the stochastic notional (balance) for the balance guaranteed swap and the fixed, and unknown at time zero, coupons that are collected over the period on one side and $U_{t}, \rho_{t}$, the amortising notional given by the upper curve of low CPR scenario and corresponding fixed coupons on the other side. The price of this swap is given by the spread rate $y$ in this structure and it may not coincide with the spread $\delta$ from a par calculation on 
the hedging amortising swap. A lower $y$ may be justified to cover the premia on interest rate derivatives upfront costs and the unhedged risk area highlighted in Figure 4.

If $L_{t}$ is the LIBOR fixed at time $t$ and $w_{t}$ represents the weight that will make the notional of the receiver swaptions equal to the difference between the upper and lower curve then the net payoff to the seller of a balance guaranteed swap at the end of period $[t, t+1]$, is

$$
N_{t}\left(c_{t}-L_{t}-y\right) \Delta_{t}+U_{t}\left(1-w_{t}\right)\left(L_{t}+\delta-\rho_{t}\right) \Delta_{t}
$$

There is no guarantee that this payoff will be positive all the time in all market scenarios.

Here we propose a different pricing mechanism that will circumvent the swaptions exercising problem. We propose hedging the risk posed by selling a balance guaranteed swap with a portfolio of an amortising swap off the upper curve as before and a series of amortising floors with notional determined again by the difference between the upper and lower curve. The exercise price of the floors will be the same as the exercise price of the swaptions so both sets of instruments have the same payoff when in the money. However, the floors do not have any downside so the seller will not have any outflow associated with the floors. For this reason, the floors will always be more expensive than the swaptions but the seller also has two major advantages. First, there is no economic decision to be made over the life of the swap. If an option on the floor (i.e., a floorlet) is in the money, the options are exercised and the same economic outcomes related to the managing of the balance guarantee swap are realised for that period. Second, even if they are not needed for notional compression, the floors will always be exercised if they are in the money. The additional cash flow will offset some of the increased premia paid for the floors when the swap is sold.

Another possibility would be to replicate a balance guaranteed swap with an amortising swap off the lower curve and a portfolio of caps with exercise price equal to the difference between the fixed leg rates of the amortising swap and the price of the amortising swap. The caps will help to bridge the gap between LIBOR and fixed coupon payments. 
There are similar advantages in terms of managing the hedging portfolio. Table 2 illustrates the flow of payments under this hedging strategy. The net payment to the seller of a balance guaranteed swap is

$$
N_{t}\left(c_{t}-L_{t}-y\right) \Delta_{t}+U_{t}\left(L_{t}+\delta-\rho_{t}\right) \Delta_{t}+w_{t} U_{t} \max \left(L_{t}+\delta-\rho_{t}, 0\right) \Delta_{t}
$$

This shows that the possible negative payments faced by the underwriter of a balance guaranteed swap are confined to the region where the balance of the collateral portfolio is outside the chosen CPR region.

\section{Insert Table 2 Here}

The LIBOR-base swaps are difficult to price mainly because there is no model available for an interest rate variable such as the Bank of England base rate (BBR). The historical data for the BBR indicate that for long periods this rate is constant and the dynamics consists only for up or down jumps given by the decisions of the economic monetary committee. While the LIBOR leg of the swap could be priced as usual off the forward curve, the BBR leg of the swap is difficult to price. For this instrument there is an even more stringent need for a good macroeconomic forecasting model that will help generate projections of the BBR under various future economic scenarios. The sub-prime crisis clearly demonstrated that it is difficult to forecast the timing and size of the reduction in BBR. While a LIBOR-based swap is without any doubt very useful, the pricing needs once again needs to be done looking at fundamental macroeconomic analysis, no-arbitrage principle being of little help in this case.

\section{Conclusions}


Real estate markets represent a very large proportion of the total wealth in developed countries. Yet, the risk management tools available for hedging real-estate risk are very much in their infancy and have problems ranging from illiquidity of trading to lack of theoretical development in terms of modelling. In this paper, we surveyed the set of financial instruments available for the management of risks arising in European property markets. Given the incomplete character of real-estate markets, we advocate a suitable pricing and hedging framework.

A special place is dedicated to mortgage-backed securities which require structured swaps capable of handling the embedded prepayment risk and default risk. We discuss some of the risk management problems faced by asset managers of RMBS deals and we suggest some solutions.

\section{References}

Baran, L.C., Buttimer, R.J., and Clark, S.P., 'Calibration of a Commodity Price Model with Unobserved Factors: The Case of Real Estate Index Futures', Review of Futures Markets, Vol. 16, 2008, pp. 455-469.

Baum, A., 'Property Futures', Journal of Property Valuation and Investment, Vol. 1, 1991, pp. 235-240.

Black, D., Success and Failure of Futures Contracts: Theory and Empirical Evidence, Monograph Series in Finance and Economics, Monograph 1986-1. New York University, 1986.

Bjork, T., and Clapham, E., 'On the Pricing of Real Estate Index Linked Swaps', Journal of Housing Economics, Vol. 11, 2002, pp. 418-432.

Buttimer, R.J. Jr., Kau, J.B., and Slawson, C.V., 'A Model for Pricing Securities Dependent upon a Real Estate Index', Journal of Housing Economics, Vol. 6, 1997, pp. 16-30. 
Carlton, D. W., 'Futures Markets: Their Purpose, Their History, Their Growth, Their Success and Failures' Journal of Futures Markets, Vol. 4, 1984, pp. 237-271.

Case, K. E., Quigley, J.M. and Shiller, R.J., 'Home-Buyers, Housing, and the Macroeconomy.' In Anthony Richards and Tim Robinson (Eds.), Asset Prices and Monetary Policy, (Reserve Bank of Australia, 2004), pp. 149-188.

Case, K. E., and Shiller, R.J., 'The Efficiency of the Market for Single Family Homes',' American Economic Review, Vol. 79, 1989, pp. 125-37.

Case K. E. and Shiller, R.J., 'Forecasting Prices and Excess Returns in the Housing Market', AREUEA Journal, Vol. 18, 1990, pp. 253-273.

Case, K. E. and Shiller, R.J., 'Mortgage Default Risk and Real Estate Prices: The Use of Index Based Futures and Options in Real Estate', Journal of Housing Research, Vol. 7, 1996, pp. 243-58.

Case, K. E., Shiller, R.J. and Weiss, A.N., 'Index-Based Futures and Options Trading in Real Estate', Journal of Portfolio Management, Vol. 19, 1993, pp. 83-92.

Ciurlia, P. and Gheno, A., 'A Model for Pricing Real Estate Derivatives with Stochastic Interest Rates', Working Paper, (Munich Personal RePEc Archive, No. 9924 , 2008).

Clayton, J. "Commercial Real Estate Derivatives: They're Here... Well, Almost." PREA Quarterly, Winter 2007), pp. 68-71.

Englund, P., Hwang, M. and Quigley, J. 'Hedging Housing Risk', Journal of Real Estate Finance and Economics, Vol. 24, 2002, pp. 167-200.

Fabozzi, F. and Tunaru, R., 'Pricing Models for Real-Estate Derivatives', Working Paper, (Yale School of Management, International Center for Finance, 2009).

Fisher, J. D., 'New Strategies for Commercial Real Estate Investment and Risk Management', Journal of Portfolio Management, Vol. 32, 2005, pp. 154-161.

Hinkelman, C. and Swidler, S., 'Trading House Price Risk with Existing Futures

Contracts'. Journal of Real Estate Finance and Economics, Vol. 36, 2008, 37-52.

Horrigan, H. T., Case, B., Geltner, D., and Pollakowski, H.O., 'REIT-Based Commercial Property Return Indices: A Model to Support and Improve Segment-Specific Investment in the Real Estate Markets.' , Working Paper, (MIT Working Paper, 2009).

Geltner, D. and Fisher, J., 'Pricing and Index Considerations in Commercial Real Estate Derivatives', Journal of Portfolio Management, Special Real Estate Issue, 2007, pp. 99 -117.

Goodman, L. and Fabozzi, F., 'CMBS Total Return Swaps', Journal of Portfolio Management, Special Issue, 2005, pp. 162-167

Lo, A. and Wang, J. ,'Implementing Option Pricing Models When Asset Returns Are Predictable', Journal of Finance, Vol. 50, 2005, pp. 87-129. 
Otaka, M. and Kawaguchi, Y., 'Hedging and Pricing of Real Estate Securities under Market Incompleteness', Working Paper, MTB Investment Technology Institute Co., Ltd., Tokyo 2002.

Patel, K. and Pereira, R., 'Pricing Property Index Linked Swaps with Counterparty Default Risk', Journal of Real Estate Finance and Economics, Vol. 36, 2008, pp. 5-21.

Pavlov, A. D., 'Competing Risks of Mortgage Termination: Who Refinances, Who Moves, and Who Defaults?', Journal of Real Estate Finance and Economics, Vol. 23, 2001, pp. $185-211$.

Schwartz, E. and Smith, J.E., 'Short-Term Variations and Long-Term Dynamics in Commodity Prices', Management Science, Vol. 46, 2000, pp. 893-911.

Seiler, M.J., Webb, J.R., and Myer, N.F.C. 'Diversification Issues in Real Estate Investment', Journal of Real Estate Literature, Vol. 7, 1999, pp. 163-179.

Shiller, R. J. and Weiss. A.N., 'Home Equity Insurance', Journal of Real Estate Finance and Economics, Vol. 19, 1999, pp. 21-47.

Shiller, R.J., 'Derivatives Markets for Home Prices', Yale Economics Department Working Paper No. 46, (Cowles Foundation Discussion Paper No. 1648, 2008).

Shiller, R.J., 'Measuring Asset Value for Cash Settlement in Derivative Markets: Hedonic Repeated Measures Indices and Perpetual Futures', Journal of Finance , Vol. 68, 1993, pp. 911-931.

Syz. Juerg M. Property Derivatives. (Wiley: Chichester, 2008).

Titman, S. and Torous, W. 'Valuing Commercial Mortgages: An Empirical Investigation of the Contingent-Claim Approach to Pricing Risky Debt', Journal of Finance, Vol. 44, 1989, pp. 345-373.

Webb, J.R., Curcio, R.J., and Rubens, J.H., 'Diversification Gains from Including Real Estate in Mixed-Asset Portfolios', Decision Sciences, Vol. 19, 1988, pp. 434-452. 


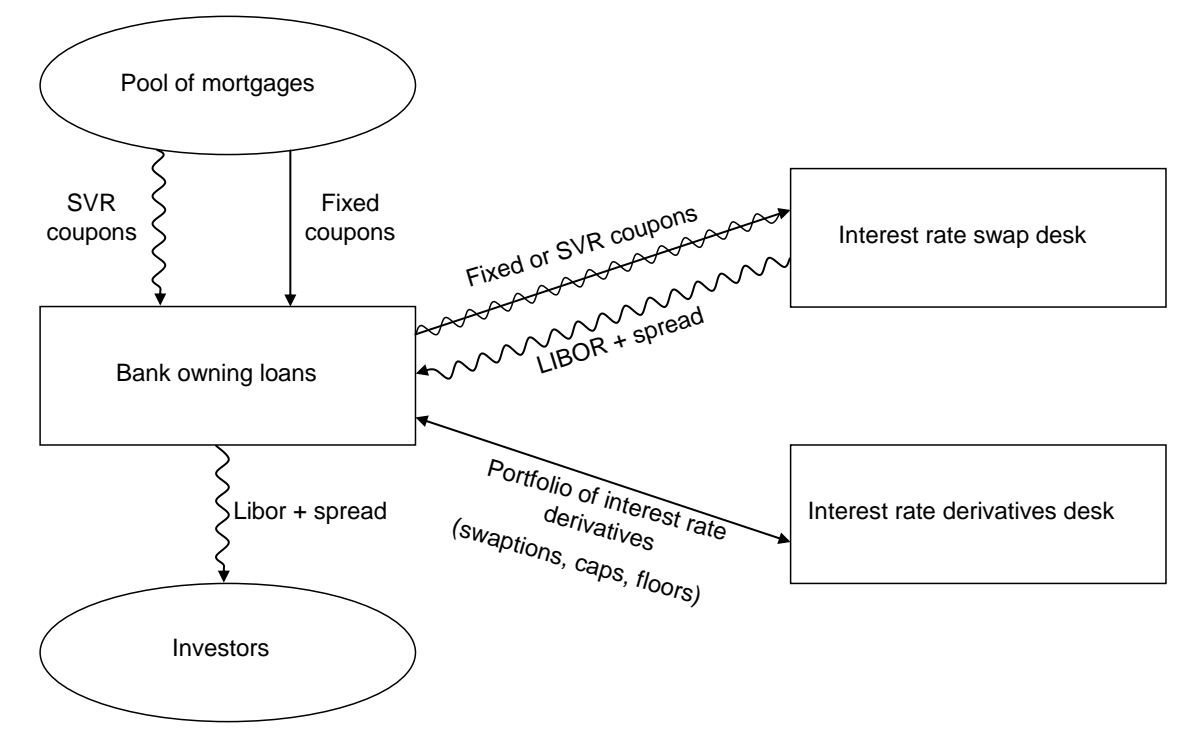

Figure 1. The main components affecting a balance guaranteed swap linked to a portfolio of mortgage loans. The SVR is the standard variable rate that banks charge their mortgage borrowers when their mortgage switches from fixed the floating. It is driven by the official base rate but its exact value is at the discretion of the bank. 


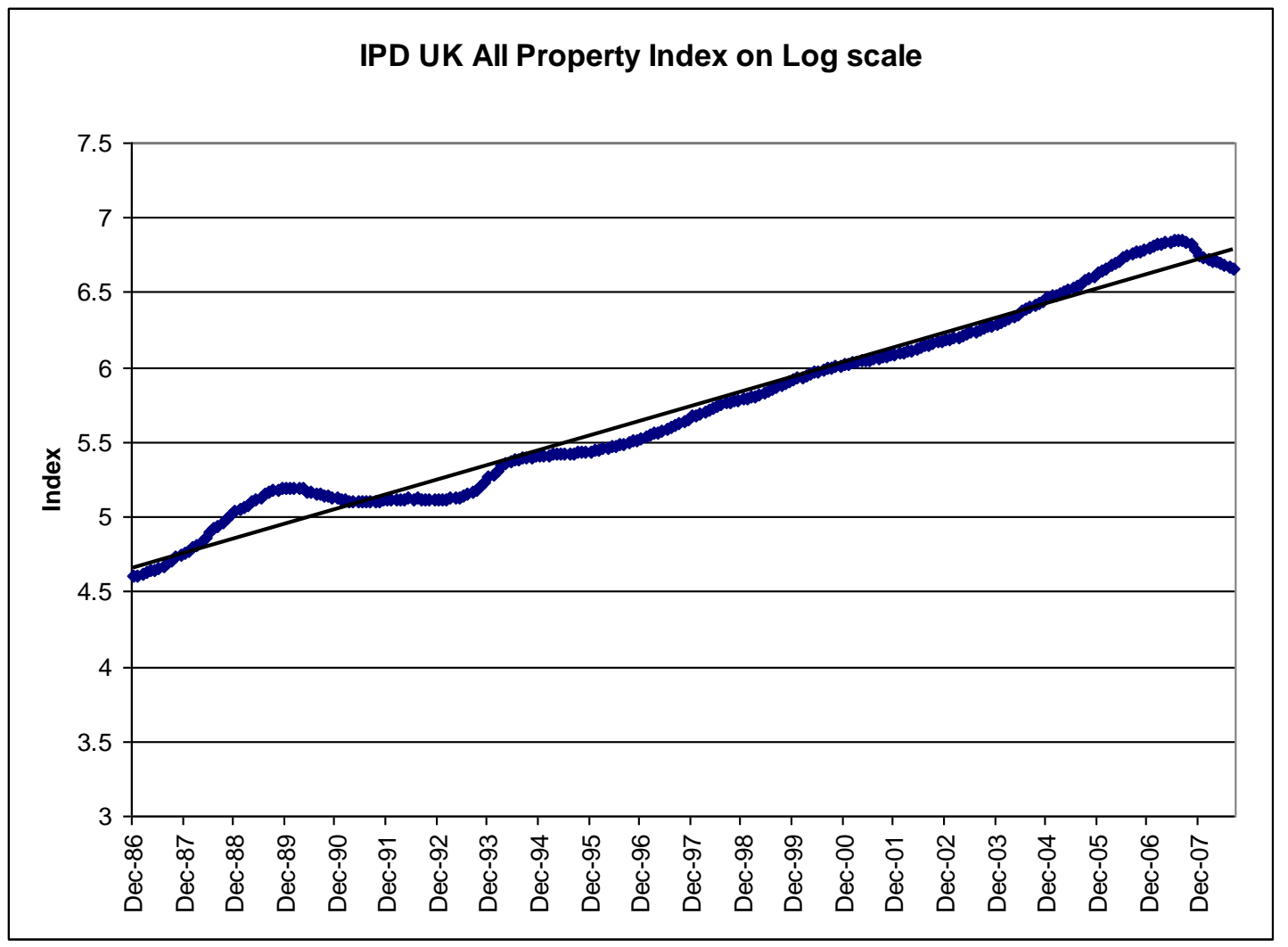

Figure 2. Historical monthly data for the IPD UK Monthly index on the log scale. The series displays a linear time trend. 


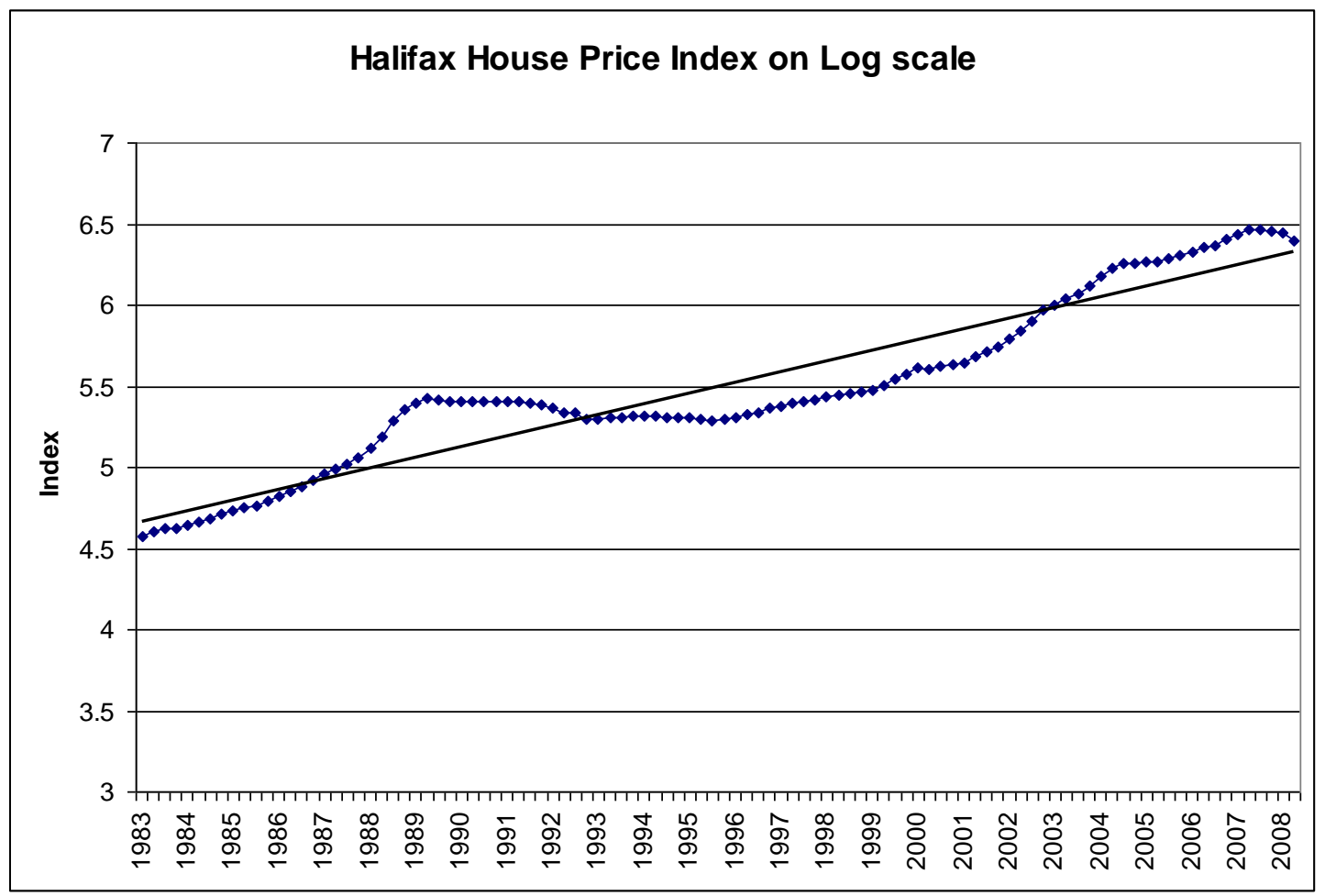

Figure 3. Historical quarterly data of the Halifax House Price Index (HHPI) on the log scale. 


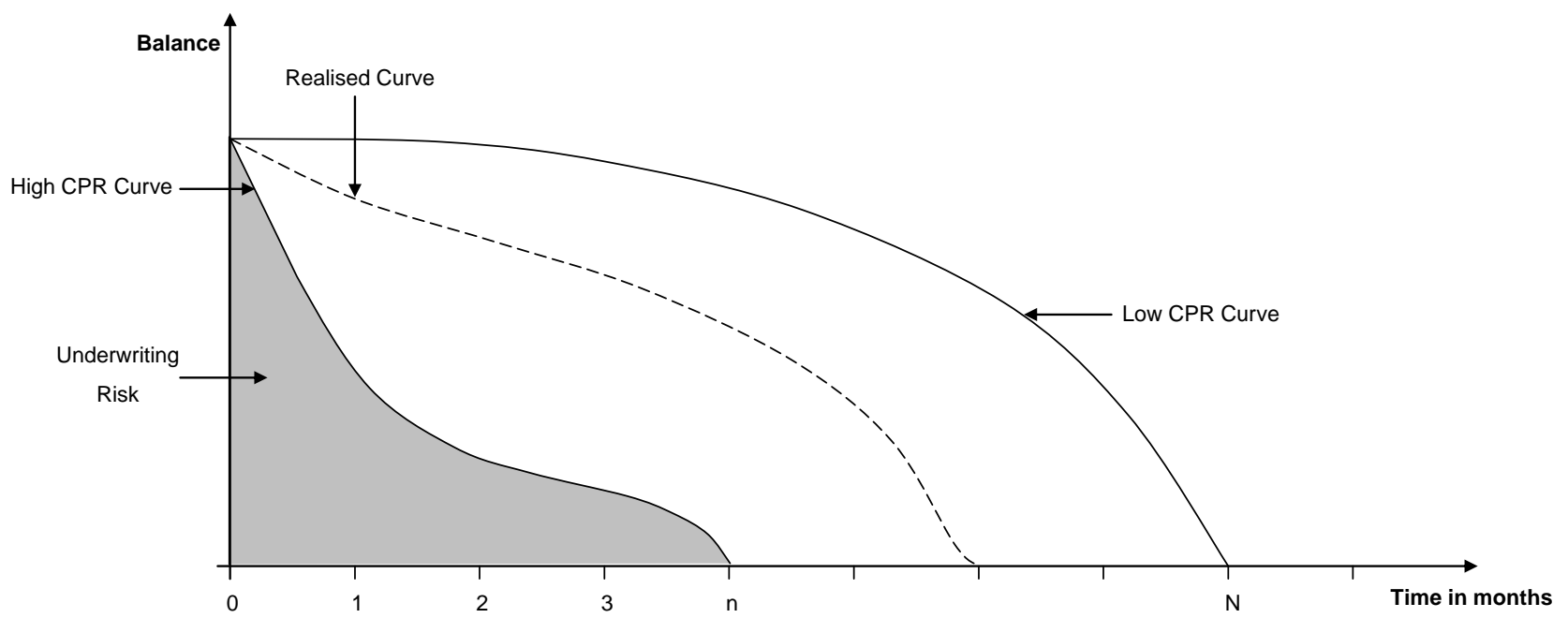

Figure 4. The curves taken into consideration for pricing and managing a balance guaranteed swap. All three curves (high CPR curve, realised curve, and low CPR curve) refer to total balance of a portfolio of mortgage loans that are the collateral in a transaction. 
Table 1

Cash flows when structuring a balance guaranteed swap with amortising swaptions

The structure of payoffs faced by the seller of a balance guaranteed swap and its counterparties. For all payments, $\Delta_{t}$ is the day time accrual for the period $[\mathrm{t}, \mathrm{t}+1] ; N_{t}, c_{t}$ are the stochastic notional (balance) for the balance guaranteed swap and the fixed, and unknown at time zero, coupons that are collected over the period; $L_{t}$ is the LIBOR fixed at time $t ; U_{t}, \rho_{t}$ are the amortising notional given by the upper curve of the low CPR scenario and corresponding fixed coupons; $\delta$ is the amortising swap price; $w_{t}$ represents the weights that will make the notional of the receiver swaptions equal to the difference between the upper and lower curve. The price of the balance guarantee swap is given by spread rate $y$ and this is the spread that is offered by the seller and accepted by the buyer, it is not a spread resulting from a par swap calculation.

\begin{tabular}{|l|l|l|l|l|}
\hline & & \multicolumn{3}{|c|}{ Payoff at time t+1 } \\
\hline Product & Leg & Buyer BGS & Seller BGS & Hedges Outside \\
\hline \multirow{2}{*}{$\begin{array}{l}\text { Balance guaranteed } \\
\text { swap }\end{array}$} & Fixed & $-N_{t} c_{t} \Delta_{t}$ & $N_{t} c_{t} \Delta_{t}$ & - \\
\cline { 2 - 5 } & Libor & $+N_{t}\left(L_{t}+y\right) \Delta_{t}$ & $-N_{t}\left(L_{t}+y\right) \Delta_{t}$ & - \\
\hline \multirow{2}{*}{ Amortising swap } & Fixed & - & $-U_{t} \rho_{t} \Delta_{t}$ & $U_{t} \rho_{t} \Delta_{t}$ \\
\cline { 2 - 6 } & Libor & - & $-U_{t}\left(L_{t}+\delta\right) \Delta_{t}$ & $-U_{t}\left(L_{t}+\delta\right) \Delta_{t}$ \\
\hline \multirow{2}{*}{ Swap from swaption } & Fixed & - & $w_{t} U_{t} \rho_{t} \Delta_{t}$ & $-w_{t} U_{t} \rho_{t} \Delta_{t}$ \\
\cline { 2 - 5 } & Libor & - & $-w_{t} U_{t}\left(L_{t}+\delta\right) \Delta_{t}$ & $+w_{t} U_{t}\left(L_{t}+\delta\right) \Delta_{t}$ \\
\hline
\end{tabular}


Table 2.

Cash flows when structuring a balance guaranteed swap with amortising floors

The structure of payoffs faced by the seller of a balance guaranteed swap and its counterparties when hedging with floors. For all payments. $\Delta_{t}$ is the day time accrual for the period $[\mathrm{t}, \mathrm{t}+1]$; $N_{t}, c_{t}$ are the stochastic notional (balance) for the balance guaranteed swap and the fixed, and unknown at time zero, coupons that are collected over the period; $L_{t}$ is the LIBOR fixed at time $t$; $U_{t}, \rho_{t}$ are the amortising notional given by the upper curve of low CPR scenario and corresponding fixed coupons; $\delta$ is the amortising swap price; $w_{t}$ represents the weights that will make the notional of the floors equal to the difference between the upper and lower curve. The price of the balance guarantee swap is given by spread rate $y$ and this is the spread that is offered by the seller and accepted by the buyer, it is not a spread resulting from a par swap calculation.

\begin{tabular}{|l|l|l|l|l|}
\hline & & \multicolumn{4}{|c|}{ Payoff at time $\mathrm{t}+1$} \\
\hline Product & Leg & Buyer BGS & Seller BGS & Hedges Outside \\
\hline $\begin{array}{l}\text { Balance } \\
\text { guaranteed } \\
\text { swap }\end{array}$ & Fixed & $-N_{t} c_{t} \Delta_{t}$ & $N_{t} c_{t} \Delta_{t}$ & - \\
\cline { 2 - 6 } & Libor & $+N_{t}\left(L_{t}+y\right) \Delta_{t}$ & $-N_{t}\left(L_{t}+y\right) \Delta_{t}$ & - \\
\hline $\begin{array}{l}\text { Amortising } \\
\text { swap }\end{array}$ & Fixed & - & $-U_{t} \rho_{t} \Delta_{t}$ & $U_{t} \rho_{t} \Delta_{t}$ \\
\cline { 2 - 6 } & Libor & - & $-U_{t}\left(L_{t}+\delta\right) \Delta_{t}$ & $-U_{t}\left(L_{t}+\delta\right) \Delta_{t}$ \\
\hline $\begin{array}{l}\text { Floorlet } \\
\text { payoff }\end{array}$ & & - & $w_{t} U_{t} \max \left(\rho_{t}-L_{t}-\delta, 0\right) \Delta_{t}$ & $-w_{t} U_{t} \max \left(\rho_{t}-L_{t}-\delta, 0\right) \Delta_{t}$ \\
\hline
\end{tabular}

